\title{
Network governance and the Urban Nexus of water, energy, and food: lessons from Amsterdam
}

\author{
Moises Covarrubias* ${ }^{*}$, Gert Spaargaren and Ingrid Boas
}

\begin{abstract}
Background: Silo-thinking stands for one-dimensional and sectorial policy and decision-making in which natural resources managers do not reflect on interrelations between different sectors involved in the management of resources. Nexus-thinking stands out as a way of breaking down silos by identifying and understanding the interconnectedness of multiple resource flows within a determined spatial and temporal context, as in our case study of the flows of water, energy, and food (WEF) in the city of Amsterdam. To further the conceptualization and analysis of the Urban Nexus, this research introduces the theoretical perspective of networks and flows as developed in sociology by Manuel Castells. It offers a set of concepts to analyze how networks of WEF integrate or fail to do so, what the main actors are in connecting and configuring WEF networks, and how they interact.

Method: We analyze how the structure and function and power dynamics of networks play out in the WEF Nexus. We use the city of Amsterdam as a case study because this city offers examples of how networks of provisioning are being integrated in innovate ways.

Results: Amsterdam managed to realize a certain level of nexus dynamics in its existing WEF networks. The nexus in Amsterdam so far has materialized at a start-up or experimental level which proved feasible for trying out innovative approaches towards sustainability in interconnected flows of WEF.

Conclusions: However, the studied projects still have to find their way in terms of becoming more prevailing modes for organizing water, energy, and food provisioning in the future.
\end{abstract}

Keywords: Urban Nexus, Governance, Networks and flows, Water-energy-food

\section{Introduction}

Within natural resources management, silo-thinking stands for one-dimensional and sectorial decision-making in which the involved actors do not reflect on the cross-sectorial linkages or interrelations between different scales in the management of natural resources. It hinders informational exchange and collaboration, concerning synergies and trade-offs between different resources systems-e.g., water, energy, and food-which are often approached as single and independent sectors [1]. Such lack of cross-sectorial management has been discussed through different concepts, such as integrated water resource management, environmental policy integration,

\footnotetext{
* Correspondence: moises.covarrubiasperez@wur.nl

Environmental Policy Group, Wageningen University and Research Centre, P.O. Box 8130, Nl-6700 EW Wageningen, The Netherlands
}

earth system governance, etcetera (for overviews, see [25]). The concept of the nexus is the latest one seeking to push forward a cross-sectorial agenda, focused on the domains of water, energy, and food. Nexus thinking is about breaking down silos; it emerges as a way of thinking to identify and understand the interconnectedness of multiple resource flows within a particular spatial and temporal context-for instance, the flows of water, energy, and food in a city. The nexus approach then is a form of systems thinking which focuses on the inter-linkages between natural resources and the ways in which the linkages are or could be managed and steered into more sustainable and integrated configurations [6].

In this paper, we focus on the urban dimension of the nexus. In the field of WEF management, "many cities in the world still rely on outdated modes of planning 
notwithstanding that planning is central to achieving sustainable urban development" [7]. Cities are thus challenged to develop innovative modes of governing and planning for the sustainable provisioning of WEF, modes of planning that no longer address WEF as single, independent, and isolated flows, infrastructures, and systems. What the nexus approach suggests is that sustainability improvements in one domain (e.g., water) are intimately related to the sustainability gains or losses in other domains (e.g., energy and food). Such cross-sectorial modes of steering and planning of material flows in the city represent an approach to governance that we refer to as the "Urban Nexus." Cities are the places where a critical mass of actors, networks, infrastructures, and resource flows come together with high density [8] and under the responsibility of designated authorities operating at city level.

In scientific literature, the study of the nexus has already advanced on researching connectivity of WEF resources at global, national, and regional scales (see e.g., in [9-12]). Yet, comparatively, the urban scale has received less attention [13], although it is a rapidly emerging field of research (see [14-16]). Clearly, the urban domain and the WEF nexus taking shape at city levels are not independent from global, regional, and national scales. Cities source WEF resources, through networks of provisioning, from places out of their territorial boundaries where resources are extracted, produced, and transported from [17]. Yet, it is the urban scale where connections between resources and users are concentrated the most and where global flows (such as WEF) intersect [18]. The urban is also a key site of innovation and experimentation [19], also in the field of the nexus. This article therefore further zooms in on the urban dimension of the WEF nexus to get a better sense of this emergent form of governance [14].

To further the analysis of the Urban Nexus, this research introduces the theoretical perspective of "networks and flows" as developed in sociology by Manuel Castells and as applied within environmental studies by [20,21], among others. While most studies on the nexus adopt a quantitative methodology focused on the material flows involved (see for example Discussions in [11, 13, 17-23]), few authors examine the socio-political processes which help to explain the emergence or failure of nexus governance in the city (see Discussions in $[14,24])$. Those that do examine socio-political questions in the provision of WEF often use a critical discursive or political economy perspective to reveal dimensions of power and inequality in nexus governance (e.g., [2]). We argue that a network approach is particularly suitable when considering how complex socio-technical systems interact and overlap in the provisioning of WEF in a more integrated and sustainable way. Such an approach emphasizes how WEF networks overlap with respect to their operational structures, their functions, their material flows, and their dynamics of end-use and provision. Studying existing empirical WEF networks can be interesting both for their synergies and the prevention of side effects as for the conflicts and new forms of competition for authority they represent.

The study focuses on Amsterdam. This urban area provides an example of innovation and integration of its provisioning networks for WEF. Amsterdam strives to become a sustainable and carbon neutral city. It aims to reduce by $75 \%$ its $\mathrm{CO}_{2}$ emissions by 2040 (compared to 1990) [28]. To attain these goals, Amsterdam aims to increase its renewable energy production and consumption, become a more circular city by recovering energy and nutrients from waste and wastewater flows $[29,30]$, and further promote the use of bikes as medium of transport of goods [31] (among other measures). As a way to trigger the accomplishment of these goals, Amsterdam aims to become an urban laboratory to facilitate innovation around its provisioning systems [32]. A number of projects have already been explored for their contribution to Urban Nexus thinking and governance within WEF domains (for overviews, see $[25,26])$. We analyze to what extent some of the projects make use of and benefit from concepts and dynamics as put forward by the networks and flows perspective to Urban Nexus [27]. In this way, we are better able to discuss the conditions for the projects to become more mainstream. We show how values, power, and structural factors condition the adoption of an Urban Nexus approach by managers, operators, and practitioners of WEF networks. We seek to demonstrate how new groups of actors-referred to as the switchers and programmers of WEF networks-play a crucial role in building WEF connections and in reconfiguring existing systems of provision of energy, water, and food.

The paper elaborates as follows. The "A network and flow perspective to the Urban Nexus" section presents the theoretical framework based on insights from the sociology of networks and flows as developed by Manuel Castells. This framework is used to structure the empirical findings. The "Methods" section introduces the methods used to conduct this research. The "Results and discussions: Lessons from Water, Energy, and Food configurations in Amsterdam" section presents the cases studied, and then, it discusses the empirical findings through the lens of the sociology of networks and flows. The "Conclusions" section provides some conclusions on the potential of the Urban Nexus of WEF.

\section{A network and flow perspective to the Urban Nexus}

The hierarchical organization of social life is increasingly being replaced by new forms of network governance [34], a development Castells has termed the emerging "network society." Also in the case of WEF provisioning, new network dynamics replace the organizational logics 
of hierarchical and sectorial units of provisioning. Network governance refers to horizontal shifts in the social organization of cities and societies. Traditional forms of state-led governance are being replaced by new forms of network governance in which public, private, and community actors co-shape policy and decision-making processes [35]. In network governance, the boundaries between the spheres of public, private, and community sectors have become blurred and permeable [34, 36]. This has direct consequences for the ways in which power is enacted in networks of WEF. In the network society, power is no longer exercised by one central actor dominating other social actors. Societies have become organized in terms of multiple and dynamic horizontal flows resulting in heterogeneous power relations and forms of distributed power that are more fuzzy, fluent, and indeterminate [37].

In this section, we further explain the central concepts of Castells' network society and discuss how these are or can be made relevant to study to the Urban Nexus of WEF. The network and flow perspective is particularly suitable for studying the Urban Nexus as it is about connectivity of resource flows, cross-overs in social relationships, and converging dynamics in governance for sustainability. We use this network and flow approach to help illuminate what the key networks are in steering the provisioning of WEF and in what ways these networks do or do not manage to produce outcomes of more integrated forms of management, planning, and decision-making. In particular, the network concept will be used to study how WEF networks integrate or fail to do so.

To characterize social networks, we first look into its structure and function: what do networks and their interrelations look like and what are their main aims or functionalities. These basic questions are answered to be able to then analyze the dynamics of power and social change involved in the governance of WEF as networks.

\section{Characterizing networks: structure and function}

A network is an organizational structure that results out of a set of inter-connected nodes (see [33]); nodes are made up by all possible components of the network (e.g., actors, processes, policies, etc.). Networks are structures that process and configure flows [37]; flows are the streams of information and resources that circulate between and around the nodes that constitute networks [37]. In this vein, we suggest that the scope of a network indicates how extended the networks are and what the variety of flows and actors in the network is about (see an illustration in Fig. 1). For instance, in the food sector, the scope can be urban agriculture projects and practitioners that self-generate food within an urban setting, or it can refer to the global food system that produces food to markets around the world. Nodes are connected by flows [37]; how nodes operate more or less central in the network and how different nodes can be connected in more tight or loose manners refer to connectivity of networks (see an illustration in Fig. 1). For example, the structure of an urban agriculture network is determined by how it connects (or not) nodes of farmers, markets, supermarkets, and local or global food providers. Networks are furthermore characterized as dense in terms of the frequency-in terms of the time-space dynamics-and the "robustness" of their flows and connecting nodes (see an illustration in Fig. 1). For instance, the networks for the provision of urban water, energy, and food are connected not only through social actors but as well through the energy and nutrient flows (e.g., heat, or phosphorus, nitrogen, and potassium) that come along with wastewaters in the city. The scope and density of these connections tell us something about the options for recovering energy and nutrients and their application as fertilizers in food production. WEF networks are considered densely connected when a myriad of actors, flows, resources, and projects-critical mass-connect or overlap to actually recover and apply those energy and nutrients into food farming, for instance.

The function of a network refers to the set of values and goals that the network is aimed to achieve. Networks result from the interactions of social actors pursuing common values and goals (see an illustration in Fig. 2); those guide actors into the creating, organizing, and the (re)configuring of networks. We then posit to

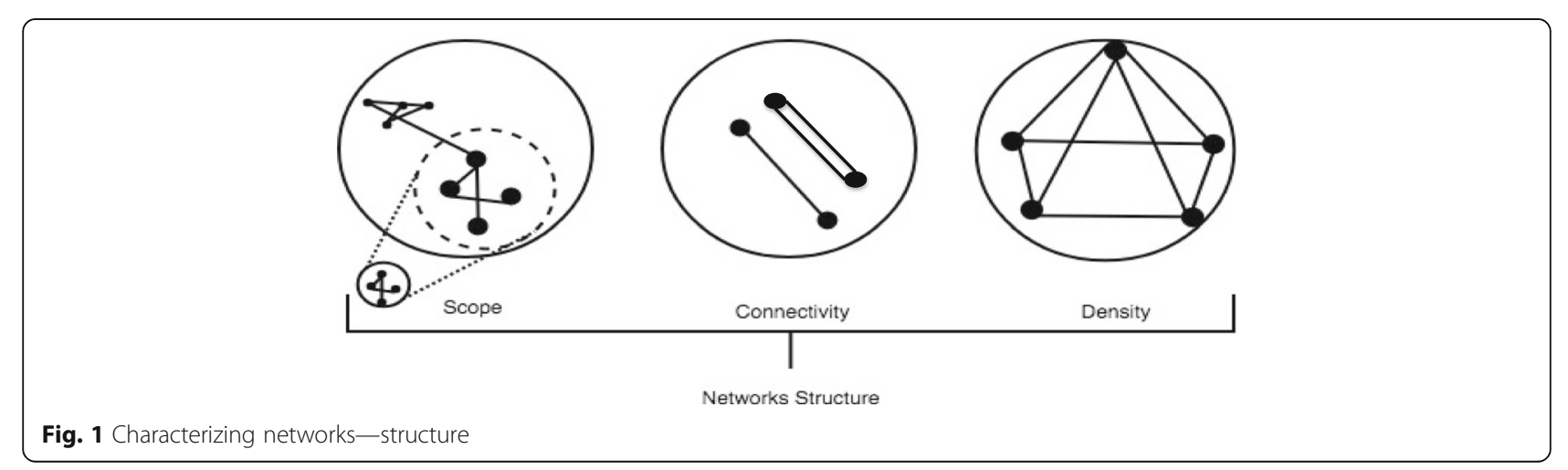




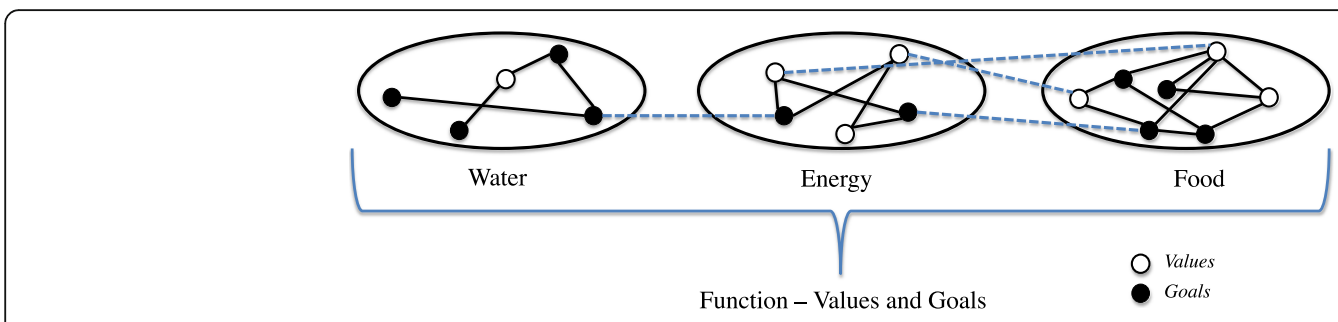

Fig. 2 Networks function—values and goals

use the concept of function to refer to values and goals of networks as inscribed in their functioning towards the realization of its interests. This function is laid down in the "code" of the network (e.g., the program). The meaning and function of nodes connecting flows depend on the functions that the network(s) is programmed with [37]. For example, in the context of governance strategies for urban climate neutrality, networks and flows of WEF interact with each other based on unifying goals (e.g., $\mathrm{CO}_{2}$ emissions reduction goals) for neutralizing the anthropogenic impact of cities in their commitment towards sustainability values. Functions are not only inscribed into the network via network programs. The values and goals represented by the network program are being acted upon by network actors, e.g., utility managers, regulators, consumers, and NGOs.

In short, to examine and understand the Urban Nexus of WEF networks, it is important to consider their goals, values, actors, nodes, and flows and to analyze how these social and material components of networks are involved in successful or failed integration in the context of the urban WEF nexus.

Next to functional and structural factors, power dynamics play a crucial role in allowing for a nexus of WEF networks to come about and for shaping the level and the kind of integration within the relevant networks.

\section{Power in networks: power dynamics in WEF networks}

Dynamics of power inform the possibilities for social change towards more integration or collaboration between WEF networks. Power dynamics, in contemporary networks, deserve special attention since these represent new dynamics of change when compared to older organizational forms (e.g., state-organized WEF provisioning after the Second World War). According to Castells [37], power in networks comes in four dimensions. Next to networked power-as the most classical form of old and concentrated power in networks-there are three more power dynamics in networks that deserve analytical attention. In the context of the WEF nexus, whether or not and how networks emerge across WEF sectors is shaped by the (i) networked power, (ii) network power, (iii) networking power, and the (iv) network-making power exercised by switchers and programmers (in terminology of [37]): (i) Networked power relates to (a) the actors dominating the processes of decision- and policymaking, (b) the sectors competing for dominance in the nexus debate, (c) the WEF sectors competing to determine what the standard approaches are to tackle common urban challenges (e.g., climate neutrality roadmaps or measures), and (d) the actors that actually establish rules for inclusion and exclusion and the execution of those standards. Although this is the oldest form of power in Castells' categorization, it should not be ignored that in some contexts, this form of power still plays a role in network dynamics. Indeed, in the context of Europe, most of the utility systems have gone through liberalization schemes in which the state is not the only societal actor dominating the sphere of resources provisioning. Instead, more societal actors play a role in modern organizational networks (e.g., WEF). What networked power in this context refers to is the actual concentration or accumulation of power by particular actors within networks and their influence on the decision and policymaking of WEF provisioning.

(ii) Networks are programmed with rules to be followed by individuals and actors. These rules relate to network power [37]. This relational capacity of power implies that coordination between actors or networks relates to the imposition of rules or standards that determine the inclusion of individuals, actors, and networks into (the nexus of) networks. For example, in the context of water-energy nexus, integrating decisionmaking or synergies between these two sectors might be conditioned by exclusivity rights from each sector that do not actually allow for one sector to intervene or participate in the other one. For instance, some water companies are restricted to produce and distribute energy because of exclusivity rights (rules) granted to the latest, and vice versa.

(iii) Once the rules or standards governing networks are determined, networking power [37] plays out as a gatekeeping capability towards any individual aiming to join a network. Networking power thus stands for the capability of certain actors for actually including or excluding individuals or 
organizations from networks (e.g., excluding tourism sectors from the nexus of WEF, or by restricting the nexus and its political attention exclusively within WEF sectors). Inclusion and exclusion are based particularly on the extent to which the scope, values, goals, or interests of the incoming party matches or are compatible, with those of the actors already included in the host network(s). In giving shape to networks, dynamics of power play out far beyond the imposition of rules and the exercising of gatekeeping capabilities. Power is also a matter of concentration and allocation of such relational capacity held by particular actors and networks. Distribution of power is then the capacity of concentrating influence by one or some actors and networks over the rest of actors or networks.

(iv) Network-making power refers to the capabilities of actors in networks to both influence the structure of networks and their interrelations in terms of connecting actors and nodes, and the functions of networks in terms of (re)configuring the goals and values that are being pursued. These capabilities rest with groups of switchers and programmers of networks [37]. For instance, programmers from WEF networks (towards the nexus of networks) could install as a network program a goal for more integrated decisionmaking protocols between WEF sectors (nexusthinking) in which actors aim to enhance possible synergies and reduce potential trade-offs among these WEF resources systems. Then, switchers emerging in the nexus of networks are the actors that link up other actors, resources, and flows from (WEF) networks for pursuing a program of more integrated management or decision- and policy-making of WEF.

Integration of WEF networks is on the one hand an outcome of unintended actions or practices held by actors from different networks, which results in either higher or lower overlapping of networks. Integration of networks is also the result of intended actions and decisions that push forward the nexus of different networks to come about. In the latest assumption, integration results from the intended capability to control connectivity pointsswitches-for outperforming sectorial approaches and for working towards the emergence of the nexus of networks. We thus argued that the interaction of structures, functions, and power dynamics of networks play a crucial role in (re)connecting and (re)configuring WEF in higher or lesser nexus outcomes (see Fig. 3).

\section{Methods}

By means of the case of Amsterdam, we examine how networks of WEF provisioning connect, or struggle to connect, towards more sustainable configurations. We conducted a (a) document and literature review and (b) one round of semi-structured experts' interviews during April and May 2017. The documents review analyzed recent governmental publications, policy documents, and publications addressing water, energy, or food provisioning sectors in Amsterdam. The interviews $(n=14)$-held face-to-face with different managers, operators, and practitioners of the WEF networks-aimed to gather answers about the points of integration between the different networks and the social dynamics between actors and

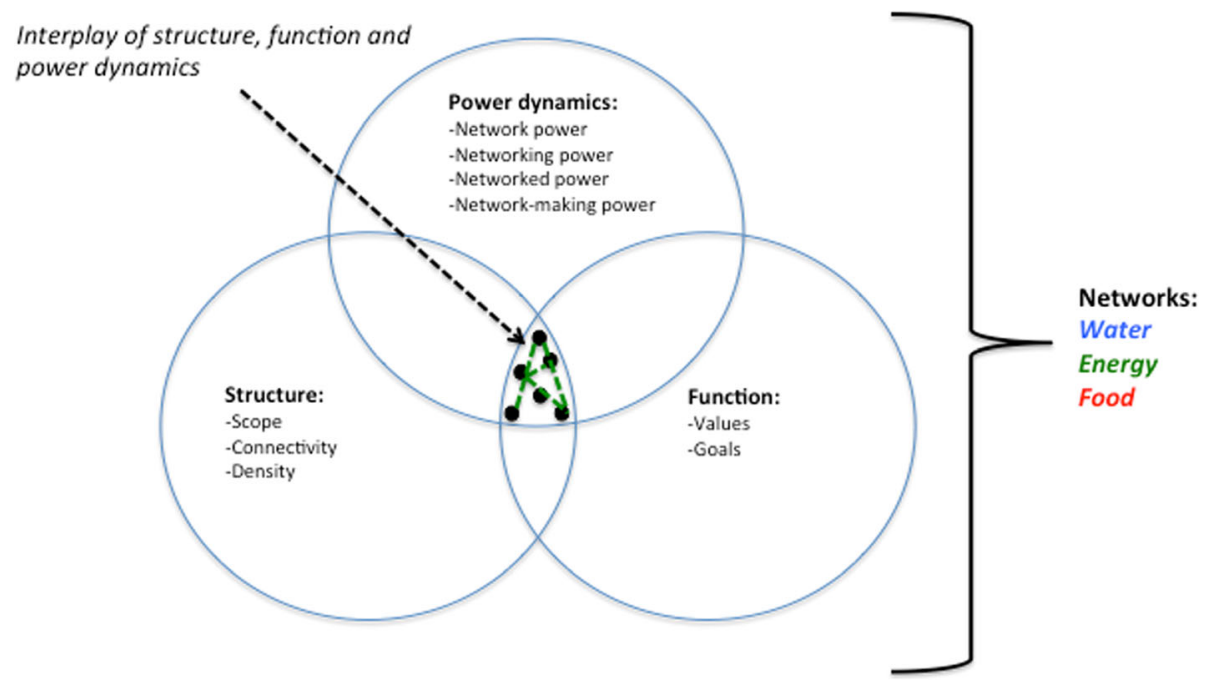

Fig. 3 Interactions of elements of networks 
networks from WEF domains. First, we employed a convenient sampling looking for knowledgeable and accessible participants. Second, we employed a snowball sampling method in order to explore WEF networks and to explore further respondents, until we established a data saturation point. Table 1 shows the list of organizations approached for the expert's interviews, the societal sector they belong to, and the provisioning sectors they work on or address. Table 1 also shows the number of interview held which is used in the "Results and discussions: lessons from water, energy, and food configurations in Amsterdam" section to refer to the results obtained and their source of data. We corroborated the information gathered from interviewees by asking different interviewees for the same information. All interviews were recorded and transcribed as soon as possible.

The cases were selected based on examples that do not only show stories of success but rather cases that show the complexity of relational dynamics between sectors of WEF towards nexus configurations. In this vein, we aim to show cases that are rich in portraying the barriers, challenges, and triggers in the emerging of the nexus. Based on this, we selected and zoomed in on three instances in the WEF sector in Amsterdam, where a nexus is actively emerging in different ways. These are (1) decarbonizing practices in the last mile of food distribution, (2) wastewater and energy links in Buiksloterham, and (3) the recovery of nutrients from wastewater plants. Each of these sub-cases mirror different ways in which network structures and functions, and power dynamics, promote or constrain the emergence of the nexus.

\section{Results and discussions: lessons from water, energy, and food configurations in Amsterdam}

In this section, we examine three nexus projects running in Amsterdam. We put particular attention on how WEF networks are being integrated in innovate ways or struggling to integrate further. We highlight what the main actors are in connecting and configuring WEF networks, the structures and functions of WEF networks, and how these interact through power dynamics. Each of the examples spotlights its attention on the concepts that better help to explain the unfolding or hurdles of more integrated management, planning, decision-making, and collaboration between WEF networks.

\section{Food-energy nexus: entrepreneurs on the road of de- carbonizing the last mile of food}

Interrelations between WEF emerge from different actors pursuing similar values and goals (e.g., sustainable development or carbon neutrality). Nevertheless, a nexus of energy and food does not always come about as a straightforward process of function alignment. The case of entrepreneurs decarbonizing the last mile of food distribution in Amsterdam provides a fruitful example of how network power-in the form of food standards-and networked power-encountered in supermarkets-do not easily allow food distribution entrepreneurs-switchers and programmers-to create a nexus between (renewable) energy and food distribution.

When it comes to powering food processes, energy and food networks densely connect to fossil fuels, but to non-renewable energy sources in a lesser extent (interviews $1-3$, see Table 1 ). In the last mile of food distribution in Amsterdam, entrepreneurial services scope to

Table 1 List of interviews

\begin{tabular}{lllll}
\hline Number of interview & Organization & Date & Societal sector & Domains \\
\hline 1 & University of Amsterdam - Smart Mobility \& Logistics & May 30, 2017 & Research & Food \\
2 & Wageningen University \& Research Centre - Urban- rural & May 23, 2017 & Research & Food \\
3 & relations in Agriculture & May 30, 2017 & Research & Food \\
4 & University of Amsterdam - Food Logistics & June 2, 2017 & Private & Food \\
5 & Food distributor in the 'last mile' & May 10, 2017 & Private & Energy \\
6 & Alliander (energy grid operator company) & May 11, 2017 & Consultancy & Energy and food \\
7 & MABS (consultancy company) & May 31, 2017 & Private & Energy \\
8 & AEB (waste to energy) & May 24, 2017 & Community & Food \\
9 & Urban farming expert and practitioner & May 10, 2017 & Public & Water \\
10 & Waternet (water network company) & May 16, 2017 & Public & Water \\
11 & Waternet & May 09, 2017 & Public & Water \\
12 & Waternet & May 19, 2017 & Public & Water, energy, and food \\
13 & Amsterdam Rainproof (initiative by Waternet) & May 16, 2017 & Public & Water, energy, and food \\
14 & Urban Planning Department of the City of Amsterdam & May 29, 2017 & Public & Water, energy, and Food \\
\hline
\end{tabular}


deliver food from wholesalers to food service providers (hotels, restaurants, and cafes) by employing electric and conventional bikes (interviews 1-3). Those services aim to deliver a more sustainable and local option for connecting food processes-connecting wholesaling with distribution and food access. This connection aims to replace the dominant practice of moving food in the city from A to B by means of CNG and diesel by gradually shifting towards the employment of electric means of transport or human-energy-based transport (interviews $1,3-5)$. Despite of such efforts and the contribution of these services to the $\mathrm{CO}_{2}$ reduction targets of Amsterdam, the share of those initiatives reflects more as a start-up level when compared to conventional (fossil fuel-based) food distribution.

That ambition has been driven by the aim to deliver energy efficiency, affordable food, and local and sustainable food distribution in Amsterdam (interviews 1, 4, 6) [38, 39]. These ambitions closely relate with the values pursued by the energy sector, which seeks to push forward on energy efficiency, sustainability, ensuring cooperation with different societal actors, and shifting from fossil fuels to renewable energy sources for energy provisioning (interviews 5,7 ). For example, sustainability is a value that overlaps between energy and food networks. Food and its goals overlap with the energy sector, for instance, when it comes to support a local and sustainable food system (interview 4). It aims to sustainably distribute food as efficiently as possible in terms of timing, quantity, frequency, and price as compared to the conventional food system [based on fossil fuels and longer distances of sourcing] (interviews $1,3,8)$. This implies that not only food distribution needs to grow in energy efficiency with regard to its timing, frequency, and quantity of deliveries between wholesalers and retailers or food service providers. It is also of high importance that such energy-food connection comes in a way that a transition to sustainable energy generation and load actually embeds and powers the transport distributing food. Although values from these networks present similarities, it is important to recall it would for the food sector be difficult to accomplish its energy neutrality visions without connecting with decarbonizing transition processes supported by the energy sector-and vice versa.

Although both networks hold similar values and goals to work towards to, those come along with power dynamics that play out through energy and food networks. Examining power relations helps to better understand why emerging projects such as e-bikes distributors experience constrains when trying to connect with more prevailing forms of provisioning. Dynamics of network power best help to explain this case by referring to the interplay between the rules of supermarkets and food service providers. Supermarkets, for instance, partially set the standards of what products are sold in the city, what size, and packaging or its specific requirements (e.g., frozen cargo or food safety standards), but also how frequently supermarkets have to get restored by food processors, wholesaler, and distributors (interviews 1, 3, 4). These standards play out as the inclusion conditionsrules-to satisfy by producers, processors, and distributors of food. For e-bikers, those standards still represent a capacity challenge (in terms of size, distance, and timing) in order to get included into the food distributors of supermarkets. Another factor playing a role in such inclusion conditions relates to the large logistics planned by supermarkets which make difficult for other individuals to get included into these planned logistics. These standards also relate to the energy network in terms of what energy can actually power food distribution and how. In other words, what energy and type of transport are able to deliver the same efficiency, timing, and frequency that supermarkets demand. Modes of distribution such as e-bikes have had difficulties for collaborating with other actors in the food network, specifically with supermarkets, because of the standards of inclusion established by these retailers.

These standards play out differently when considering the relationship between food distributors and different food receptors. For instance, standards play out differently in the relationship between e-distributors and the Horeca (hotels, restaurants, cafes). In this context, those standards, in terms of the size, distances, and timing of cargo, are more compatible with the delivering capabilities of e-bikes as such sector demands more localized distribution and food sourcing, shorter distances, and lighter cargo capacity (interviews 4, 6, 8).

Standards play out as the conditions for the inclusion or exclusion of actors from this particular nexus project. Those standards then relate to the actual exercising of networking power. From the view of the supermarkets, the standards are actually not including distributors such as e-bikers as opposed to food service providers (Horeca) who reflect more inclusive dynamics towards e-bikes distributors.

The inclusion rules that play out through networks are in part related to the allocation or distribution of power. Networked power is evidenced in the capability of supermarkets and food service providers over the energy implications of food distribution. Supermarkets are actors that have control on what, how, and when to consume, and those influence the whole food supply chain (interviews 1, 2, 3). For instance, supermarkets in Amsterdam can influence the supply chain on the side of distributors, wholesalers, processors, and producers (interview 3 ). Then, the standards that supermarkets exert in the supply chain influence the energy inputs required for provisioning food in the city. This, in turn, translates into the dominance of the fossil fuel-based logistics, via retailing, through the food supply chain. 
In the relation between e-bikers and food services providers (Horeca), networked power plays out differently when compared to supermarkets. Contrary to supermarkets, the power of the Horeca sector is rather fragmented; it does not concentrate the same critical mass of networked power as supermarkets do. The Horeca is conformed by over 5000 establishments, and most of them have their own ownership, management, logistics, providers, and operations (interviews 1, 3, 6). This has a dual effect. On the one hand, a myriad of establishments with their own logistics translates into a myriad of services providers distributing food in Amsterdam employing different types of transport which might be seen as inefficient logistics (interviews 1, 3). On the other hand, its fragmented networked power opens the opportunity to alternative food distribution providers for competing and gaining a share in supplying food distribution services to this market segment (interview 4).

Despite the hurdles discussed around network and networked power, initiatives of e-bikes distributors are breaking through into the last mile of food in Amsterdam. They do so by exercising their network-making power through their role of switchers and programmers. These initiatives challenge the dominant fossil fuel-based last mile by reconfiguring it with more sustainable practices of distribution. These initiatives emerge as switchers connecting with other actors (e.g., Horeca and urban farmers) that share a mindset alike towards "good food" and "a clean last mile of food" (interviews 4, 8).

What outstands in this project is the role of switchers and programmers that-despite of the standards and power held by supermarkets-constitute new functions, structures (e.g., scope), and aim to re-arrange power dynamics between energy and food networks. This case showed that despite of the dominance of fossil fuel usage in food transport plus the discussed power dynamics, switchers and programmers gradually gain position in the food system towards its de-carbonization. They do so via projects of action in which actors with similar structures and functions align and open the space for new practices of distribution and new setting up of actors.

\section{Water-energy nexus: wastewater to energy in Buiksloterham}

Buiksloterham is a former industrial area located in Amsterdam which has recently been used as an experimental living lab to test innovative urban solutions. In this area, Waternet, the water company responsible for all the water cycle in Amsterdam, runs an experimental project that consists of a decentralized water treatment plant to recover nutrients and energy from wastewater flows (interviews 5, 9-11) [40]. This project is the outcome of cross-sectorial dynamics of problem framing, collaboration, and decision-making in which actors such as the municipality, the urban planning department, AEB (waste-to-energy plant), Waternet, and housing corporations (in total close to 24 different parties) gathered their interests, visions, and goals (interviews 5, 911). The outcome of this project is to produce biogas and heat (interviews 9, 10, 11, 12), and by doing that, this project exemplifies a re-connection between, and re-configuration of, water-energy networks. Particularly, it connects Waternet and AEB (waste-to-energy company). We shed light on (1) competing structures and network power dynamics, (2) the deregulation of switches between networks, and (3) the roles of switchers and programmers linking and programming water and energy into the project in Buiksloterham.

Water and energy networks have similar functions and competing structures. Waternet is driven by values that aim to deliver sustainability and decentralization of the water treatment processes while guaranteeing safety of water provisioning as its core value [41]. The way the water company operationalizes its values is by closing water cycles and re-using materials [42] and by working towards climate, carbon, and energy neutrality (interviews 5, 7, 9-11). Those values and goals are similar to the ones the city of Amsterdam (towards 2040) [28, 29] and the energy sector pursue. The energy sector in Amsterdam targets to gain in sustainability, $\mathrm{CO}_{2}$ neutrality (city-level), and shifting from fossil fuels to renewable energy sources for energy supply (interviews 5, 7). Sustainability, for example, is a value that overlaps in energy neutrality visionaries from both networks when (a) the water sector aims for decarbonizing its processes and (b) the energy sector envisions shifting towards renewable energy provision. What these visionaries have in common is a shift in the energy inputs for powering the two sectors. For both sectors, the accomplishment of such goals closely depends on (a) the deployment of more renewable energy sources and (b) powering water and energy processes with renewable and recovered energy (interviews 7, 9-11). This project reflects the ambitions and efforts in Amsterdam to re-connect water and energy into more sustainable configurations.

Although water and energy networks overlap in their functions, these also experience competing structures and conflicting network power dynamics. Waternet provides all the processes related to the water cycle. This enables the water company with the control (and the accountability) to establish the rules of inclusion into this network. Its bylaws grant Waternet with the competences and accountability for provisioning water to Amsterdam, leaving out, for instance, innovators (from outside of the water company) to play a role within this network (interviews 6, 9-11). Instead, the energy network has a more diverse constellation of actors that interplay in the establishment of its rules of inclusion 
(e.g., generators, transmission managers, distributors, and co-producers are all different actors). This results in organizational rules and operational competences competing between water and energy networks. Waternet overlaps its operations with the energy network (mainly producers and distributors) competences when recovering-and consequently producing-energy from wastewater flows. Waternet is restricted to produce and distribute energy (heating) since these processes are the competence of energy producers and operators (interviews 9-11). In the same way, the scope of the energy network does not allow energy companies to intervene on water provisioning. Therefore, structures and rules from networks (such as competences and bylaws) determine the inclusion and exclusion of other actors into the discussed networks.

In this experimental project, water and energy networks are opening up their structures (primarily their scopes) to actually collaborate instead of excluding each other. This is reflected in the experimental status granted to the project, which functions as a permission to try out innovation or in other words an opening of scopes. This is explained by the networking-making power exercised primarily by the Municipality of Amsterdam, Waternet, and AEB in their roles as switchers and programmers. Through setting up experimental projects-based on a permission to try out innovation-they actually re-connect and re-program the way those networks normally work. What they do is to attenuate rules, regulations, barriers, bureaucracy, or bottlenecks that may interfere with carrying out innovations (interviews 5, 9-11, 13, 14). In other words, those constraints are de-regulated to allow for experimentation and innovation. Consequently, their exclusivity competences written in their structures and rules open and create a space and time for experimentation.

This project is in part also possible because the Municipality of Amsterdam is a shareholder in both companies-Waternet and AEB. In this way, the municipality functions as one of the switchers that re-connect, via this project, water and energy in an innovative manner to support the city ambitions. This has facilitated cooperation between these networks by means of a common working agenda, research, and projects to work towards to (interviews 5, 9-11). AEB and Waternet scopes are examples of switches from the water and energy networks allowing for water-energy reconfigurations and reconnections to emerge.

This example showed the case of de-regulation of switches (scopes) between two competing networks claiming the applicability of their own competences. It showed how critical switches, such as rules and competences, can create a connection between different actors and networks into the emergence and configuration of a specific nexus project. In this case, the structures of networks adapt as a result of more flexibility for both networks to experiment with wastewater and energy. Nevertheless, in this case, the de-regulation of switches does not yet result in a more conventional way of provisioning energy and water systems at the city level. Instead, it rather resembles an experimental momentum.

\section{Water-energy-food nexus: recovering nutrients from wastewater plants}

As discussed in the last example, structure characteristics of networks are a key puzzle in connecting different networks towards more nexus-oriented configurations. Similarly, compatibility of functions between interacting networks and their embedded network power dynamics plays a crucial role for the nexus of networks to come about. To illustrate these concepts further, we provide an example of an experimental project in Amsterdam that links water-energy-food networks.

Waternet is a water company that runs a decentralized wastewater pilot project in Buiksloterham. Decentralized wastewater systems facilitate the option to recover and close energy and nutrient cycles [43]. In Buiksloterham, Waternet separates streams of wastewater into gray and black wastewater flows [43]. This project links the processes of wastewater treatment and nutrient recoverymainly nitrogen and phosphorus-for their possible applications on fertilizer and protein (for feed) production (interviews 9-11) [44]. In connection with the WEF nexus, this project powers its processes with the energy surplus load from the waste-to-energy-plant (AEB) (interviews 5, 9-11). Wastewater does not only represent a key source of energy and nutrients, but it also represents a source of micro-pollutants (e.g., pathogens, hormones, and medicine residues) that can trigger diseases in humans $[45,46]$. This concern is reflected in the competing values safeguarding different priorities. On the one hand, those values pursue more resource circularity and sustainable development $[40,43,47,48]$, versus water safety for water users on the other hand (interviews 9-11) [49].

Waternet contributes to the city ambitions to become an urban laboratory. It experiments with phosphorous recovery from gray water treatment and its further connection in agriculture. Experimenting with this linkage has provided for Waternet with circularity, economical and operational feasibility results. Despite of the feasibility tests, taking experimental projects into more prevailing and large-scale systems of provisioning is currently not allowed by water regulations safeguarding sanitary and public health values (interviews 9-11) [49]. In a similar vein, wastewater-to-protein experiments for nutrient recovery are operationally feasible but it is restricted by sanitary regulations. Buiksloterham also hosts experiments employing food grinders to recover nutrient 
content in black wastewater flows [45]. Nevertheless, recovery of nutrients from black wastewater flows is prohibited by national and European regulations.

The previous case shows how bylaws and competences (scope), and regulations (network power), exclude the water network from distributing and commercially producing energy (and vice-versa). In contrast, in the current case, the water network is neither a commercial producer nor distributor of energy but rather a consumer of the energy network. Structures and functions of these networks do not compete when it comes to connectivity of the energy surplus of AEB and the energy consumption of the wastewater plant for the nutrient recovery. What is remarkable from this case then is not the compatibility or incompatibility of scopes between WEF but the incompatibility of values between water and food networks. In this sense, networks thus block the connectivity of particular flows or nodesswitches. In this example, this block occurs, between recovered nutrients from wastewater flows and possible food applications, as a response to presumable trade-offs (sanitary risks) and incompatibility of values (water safety).

\section{Conclusions}

Amsterdam shows a certain level of Urban Nexus progress among its WEF networks. This has been evidenced and discussed through some of the projects that cross-connect WEF flows and networks. We argue that structure, function, and power enacted through networks shape the nexus of WEF into different configurations and connections. It shows how the studied projects start to re-configure and reconnect networks with new values, goals, actors, and processes. Despite of the barriers encountered in the studied projects, switchers and programmers make a step forward towards the nexus of WEF networks, and the city ambitions, via innovative and collaborative sustainability projects.

Giving attention to strategic points of connection, for example experimental projects, is key for steering the WEF Urban Nexus into more desirable configurations. This paper provided empirical examples to understand and identify how different types of power relations, structures, and functions shape WEF networks. From the projects exemplified, some switches represented barriers, while others functioned as triggers for connecting WEF within the nexus of networks. Barriers mainly related to compatibility of values, competences, and organizational structures (e.g., safety and health concerns, standards, and policies). Those barriers have limited the growth of projects towards denser and more connected WEF flows and networks; instead, barriers have partly kept those projects in a start-up and experimenting level of development.
Pursuing cross-sectorial values and goals proved of crucial importance. These have the potential to disrupt fragmented practices from provisioning systems into more nexus-oriented outcomes. When values are compatible, it allows bringing together actors, nodes, flows, and networks into a stronger-denser and better connected-nexus network (e.g., overlapping sustainability values and goals between networks). However, both competing values and power dynamics in part hampered the cross-sectorial interaction that the nexus aims for.

Power showed to be a critical relational dynamic in the convergence of WEF systems. Network power, networked power, and network-making power have in this paper been evidenced as critical dimensions to address for further strengthening the nexus of WEF networks. On the one side, WEF networks still have to cope with current and prevailing provisioning systems that somehow impose a lock-in effect on the infrastructures, and organizational and economic factors around the way WEF systems are provided. On the other hand, the analysis of switchers and programmers provides lessons on what actors, and how, are shaping the ongoing provisioning systems (and its barriers) towards innovative reconfigurations of networks of provisioning.

It might be that many cities-as in this case Amsterdam-still depend on outdated modes of provisioning, outdated modes that do not achieve sustainable urban development of WEF. Reliance and dependency on current provisioning systems are challenges that cities need to tackle to effectively govern the WEF Urban Nexus. Further efforts are needed by switchers and programmers in their role of reconfiguring and reconnecting networks into more nexus-oriented systems of WEF provisioning.

\section{Abbreviations}

AEB: Afval Energie Bedrijf; CNG: Compressed natural gas; CO2: Carbon dioxide; Horeca: Hotels, restaurants, and cafes; UN: United Nations; WEF: Water, energy, and food

\section{Acknowledgements \\ We would like to thank to the respondents, informants, and interviewees that helped to carry out this research. \\ Funding \\ Not applicable \\ Availability of data and materials \\ The datasets used and/or analyzed during the current study (the interviews conducted, as explained in the "Methods" section) are available from the corresponding author on reasonable request.}

\section{Authors' contributions}

GS contributed to co-writing the "A network and flow perspective to the Urban Nexus" section and editing through all the sections of this paper. IB contributed to co-writing the "Results and discussions: Lessons from Water, Energy, and Food configurations in Amsterdam" section and editing through all the sections of this paper. All authors read and approved the final manuscript. 


\section{Ethics approval and consent to participate}

Not applicable.

\section{Consent for publication}

Not applicable.

\section{Competing interests}

The authors declare that they have no competing interests.

\section{Publisher's Note}

Springer Nature remains neutral with regard to jurisdictional claims in published maps and institutional affiliations.

\section{Received: 17 January 2019 Accepted: 9 April 2019}

\section{Published online: 02 May 2019}

\section{References}

1. Hoff H (2011) Understanding the nexus. Background paper for the Bonn 2011 Conference: the water, energy and food security. Stockholm Environment Institute, Stockholm

2. Allouche J, Middleton C, Gyawali D (2015) Technical veil, hidden politics: interrogating the power linkages behind the nexus. Water Altern 8:610-626

3. Boas I, Biermann F, Kanie N (2016) Cross-sectoral strategies in global sustainability governance: towards a nexus approach. Int Environ Agreem Polit Law Econ 16:449-464 https://doi.org/10.1007/s10784-016-9321-1

4. Cairns R, Krzywoszynska A (2016) Anatomy of a buzzword: the emergence of 'the water-energy-food nexus' in UK natural resource debates. Environ Sci Pol 64:164-170 https://doi.org/10.1016/j.envsci.2016.07.007

5. Wichelns D (2017) The water-energy-food nexus: is the increasing attention warranted, from either a research or policy perspective? Environ Sci Pol 69: 113-123 https://doi.org/10.1016/j.envsci.2016.12.018

6. Vogt C, Zimmermann M, Brekke K (2014) Operationalizing the Urban Nexus. Towards resource-efficient and integrated cities and metropolitan regions. GIZ and ICLEI, Bonn

7. UN Habitat (2016) Quick facts - WORLD CITIES REPORT 2016. http://wcr. unhabitat.org/quick-facts/. Accessed 19 May 2017

8. Hodson M, Marvin S, Robinson B, Swilling M (2012) Reshaping urban infrastructure. J Ind Ecol 16:789-800 https://doi.org/10.1111/j.1530-9290.2012.00559.x

9. Bazilian M, Rogner $\mathrm{H}$, Howells $\mathrm{M}$ et al (2011) Considering the energy, water and food nexus: towards an integrated modelling approach. Energy Policy 39:7896-7906 https://doi.org/10.1016/..enpol.2011.09.039

10. Endo A, Tsurita I, Burnett K, Orencio PM (2015) A review of the current state of research on the water, energy, and food nexus. J Hydrol Reg Stud https://doi.org/10.1016/j.ejrh.2015.11.010

11. Howells M, Hermann S, Welsch M et al (2013) Integrated analysis of climate change, land-use, energy and water strategies. Nat Clim Chang 3:621-626

12. Nair S, George B, Malano HM et al (2014) Water-energy-greenhouse gas nexus of urban water systems: review of concepts, state-of-art and methods. Resour Conserv Recycl 89:1-10 https://doi.org/10.1016/j.resconrec. 2014.05.007

13. Zhang C, Chen $X$, Li Y et al (2018) Water-energy-food nexus: concepts, questions and methodologies. J Clean Prod 195:625-639 https://doi.org/10. 1016/j.jclepro.2018.05.194

14. Artioli F, Acuto M, McArthur J (2017) The water-energy-food nexus: an integration agenda and implications for urban governance. Polit Geogr 61: 215-223 https://doi.org/10.1016/.jpolgeo.2017.08.009

15. Chan A (2015) Connecting cities and their environments: harnessing the water-energy-food nexus for sustainable urban development. Change Adapt Socio-Ecol Syst 2 https://doi.org/10.1515/cass-2015-0017

16. Keilmann-Gondhalekar D, Ramsauer $T$ (2017) Nexus City: operationalizing the urban water-energy-food nexus for climate change adaptation in Munich, Germany

17. Villarroel Walker R, Beck MB, Hall JW et al (2014) The energy-water-food nexus: strategic analysis of technologies for transforming the urban metabolism. J Environ Manag 141:104-115 https://doi.org/10.1016/j.jenvman.2014.01.054

18. Sassen S (2005) The Global City: introducing a concept. Glob City 18

19. Bulkeley H, Castán Broto V (2013) Government by experiment? Global cities and the governing of climate change: government by experiment? Trans Inst Br Geogr 38:361-375 https://doi.org/10.1111/j.1475-5661.2012.00535.x

20. Mol APJ, Spaargaren G (2006) Governing environmental flows: global challenges to social theory. MIT, Cambridge [etc.]
21. Spaargaren G (2003) Sustainable consumption: a theoretical and environmental policy perspective. Soc Nat Resour 16:687-701 https://doi. org/10.1080/08941920309192

22. Chen S, Chen B (2016) Urban energy-water nexus: a network perspective. Appl Energy https://doi.org/10.1016/j.apenergy.2016.03.042

23. Smajgl A, Ward J, Pluschke L (2016) The water-food-energy Nexus Realising a new paradigm. J Hydrol 533:533-540 https://doi.org/10.1016/j. jhydrol.2015.12.033

24. Tevar AD, Aelion HM, Stang MA, Mendlovic J (2016) The need for universal metrics in the energy-water-food nexus. J Environ Stud Sci 6:225-230 https://doi.org/10.1007/s13412-016-0365-x

25. Leung Pah Hang MY, Martinez-Hernandez E, Leach M, Yang A (2016) Designing integrated local production systems: a study on the food-energy-water nexus. J Clean Prod 135:1065-1084 https://doi.org/10.1016/j.jclepro.2016.06.194

26. Mannan M, Al-Ansari T, Mackey HR, Al-Ghamdi SG (2018) Quantifying the energy, water and food nexus: a review of the latest developments based on life-cycle assessment. J Clean Prod 193:300-314 https://doi.org/10.1016/j. jclepro.2018.05.050

27. Covarrubias M (2018) The nexus between water, energy and food in cities: towards conceptualizing socio-material interconnections. Sustain Sci https:// doi.org/10.1007/s11625-018-0591-0

28. Gemeente Amsterdam (2011) Economically strong and sustainable structural vision: Amsterdam 2040. http://portal.mc-4.org/uploads/1/2/1/4/ 12146463/amsterdam_climate_proof.pdf. Accessed 4 Apr 2016

29. Amsterdam G (2015) Sustainable Amsterdam: agenda for renewable energy, clear air, a circular economy and a climate-resilient city

30. AEB Amsterdam (2014) Duurzaamheidsdag

31. Gemeente Amsterdam A Green Metropole: Amsterdam Definitely Sustainable. https:/www.amsterdam.nl/publish/pages/502029/a_green_ metropole_def.pdf. Accessed 29 Mar 2016

32. Gemeente Amsterdam (2009) Amsterdam in 2020. Sustainable opportunities, sustainable future

33. van Wilden W, Oskam I, van den Buuse D et al (2016) Organising smart city projects. Amsterdam University of Applied Sciences, Amsterdam

34. Kuindersma W, Arts B, van der Zouwen MW (2012) Power faces in regional governance. J Polit Power 5:411-429 https://doi.org/10.1080/2158379X.2012.735116

35. Arts B, Tatenhove JV (2004) Policy and power: a conceptual framework between the 'old' and 'new' policy idioms. Policy Sci 37:339-356 https://doi. org/10.1007/s11077-005-0156-9

36. Bush SR, Oosterveer P, Bailey M, Mol APJ (2015) Sustainability governance of chains and networks: a review and future outlook. J Clean Prod 107:8-19 https://doi.org/10.1016/j.jclepro.2014.10.019

37. Castells M (2009) Communication power. Oxford University Press, Oxford

38. Amsterdam Smart City (2015) Last mile logistics: Foodlogica. Amst, Smart City https:/amsterdamsmartcity.com/network/foodlogica. Accessed 19 Oct 2016

39. Foodlogica (2015) FOODLOGICA - DUURZAME LOGISTIEK VOOR LOKALE MERKEN EN HORECA. http://foodlogica.com/. Accessed 19 Oct 2016

40. Metabolic, Studioninedots, DELVA Landscape Architects (2014) Transitioning Amsterdam to a circular city: circular Buiksloterham, Amsterdam. https:/www. metabolic.n//projects/circular-buiksloterham/. Accessed on 24 Apr 2019

41. Waternet (2018) Waternet - who we are. https://www.waternet.nl/en/aboutus/who-we-are/. Accessed 16 Jul 2018

42. Van Der Hoek JP, Struker A, Danschutter JEM (2013) Amsterdam as a sustainable European metropolis: integration of water, energy and material flows

43. Mijatovic S (2017) Buiksloterham - new sanitation raw materials station. Amst, Smart City https://amsterdamsmartcity.com/projects/buiksloterhamnew-sanitation-raw-materials-statio. Accessed 17 Jul 2018

44. CityZen Smart City (2017) Neighbourhood bio refinery: producing nutrients and heat from waste. In: City-Zen. http://www.cityzen-smartcity.eu/neighbourhoodbio-refinery-producing-nutrients-and-heat-from-waste/. Accessed 17 Jul 2018

45. DELVA Landscape Architects (2016) Circular Cities. Designing post-industrial Amsterdam: the case of Buiksloterham

46. FAO (2017) Chapter 2 - Health risks associated with wastewater use. http:// www.fao.org/docrep/w5367e/w5367e04.htm. Accessed 14 Aug 2017

47. Circle Economy, TNO, Gemeente Amsterdam (2016) Circular-Amsterdam a vision and action agenda for the city and metropolitan area

48. Mijatovic S (2016) Circular Buiksloterham. Amst, Smart City https:// amsterdamsmartcity.com/projects/circulair-buiksloterham. Accessed 18 Jul 2018 49. Reinstra O (2018) Waste water treatment biorefinery 